\title{
Occurrence and conversion of anhydrolutein into dehydroretinol in a freshwater fish
}

\author{
By A. B. BARUA AND R. C. DAS* \\ Department of Chemistry, Gauhati University, Gauhati 78ror4, Assam, India \\ (Received 25 February 1974 - Accepted 30 Fuly 1974)

\begin{abstract}
I. Lutein and anhydrolutein have been isolated from liver oils of freshly caught Sacco-
2. S. fossilis initially contained more dehydroretinol than tetinol; administration of anhydrolutein to the vitamin A-depleted fish resulted in the accumulation of dehydroretinol.

3. Anhydrolutein has also been isolated from the liver oils of lutein-treated, vitamin Adepleted fish.

4. The pathway of the conversion of lutein into dehydroretinol is discussed.
\end{abstract} \\ branchus fossilis.
}

The mechanism of dehydroretinol (vitamin $\mathrm{A}_{2}$ ) biosynthesis in freshwater fish has not been completely elucidated. There are claims that $\beta$-carotene (Morton $\&$ Creed, I939) and astaxanthin (Grangaud \& Moatti, I958a, b) serve as the precursors of dehydroretinol in freshwater fish. Other claims that anhydrolutein ( 3 '-hydroxy-3,4dehydro- $\beta$-carotene) serves as the precursor (Budowski \& Gross, 1965; Savithry, Krishna Mallia \& Cama, I972), are based on experiments done, not with fish, but with chicks and rats which do not usually contain dehydroretinol. Recent work done in the authors' laboratory suggests that lutein is a natural carotenoid that can act as a precursor of dehydroretinol (Barua, Singh \& Das, I973). However, the exact mechanism for this conversion is not known. The present work is an attempt to find a possible pathway for the conversion of lutein into dehydroretinol. We have demonstrated that anhydrolutein is present naturally in the liver oil of Saccobranchus fossilis and can be formed from lutein. Anhydrolutein is also an effective precursor of dehydroretinol, which suggests that the conversion of lutein into dehydroretinol may involve anhydrolutein as an intermediate.

\section{MATERIALS AND METHODS}

Light petroleum (b.p. $40^{\circ}-60^{\circ}$ ), cyclohexane, acetone and benzene were supplied by British Drug Houses (Glaxo Laboratories (India) Ltd), Bombay. Other solvents were purified by the methods described previously (Barua et al. I973).

\section{Reagents}

p-Toluene sulphonic acid was obtained from Riedel-De Haen AG, Germany. Other reagents were described previously by Barua et al. (I973). Magnesium oxide, for chromatographic adsorption analysis (British Drug Houses Ltd, Poole, Dorset), and Celite 545 (Koch-Light Laboratories, Colnbrook, Bucks.) were used for chromato-

* Present address: Department of Chemistry, Shillong College, Shillong 3, Meghalaya, India. 
graphy. Silica gel (supplied by Chemo Synthetics, Calcutta, India) $(0.25 \mathrm{~mm}$ thickness) was used for thin-layer chromatography. Two solvent systems, cyclohexanediethyl ether $(80: 20, \mathrm{v} / \mathrm{v})$ (Bolliger \& Konig, 1969) and light petroleum-benzeneethanol (60:30: 10 , by vol.), were used.

\section{Preparation of lutein and anhydrolutein}

Fresh leaves of Zea mays (collected from Shillong, India) were used as the source of lutein.

Fresh leaves $(800 \mathrm{~g})$ were ground, using an electric blender, with 21 ethanol added gradually. The ethanolic solution was saponified with $\mathrm{KOH}(200 \mathrm{~g})$ at $60^{\circ}$ for $2 \mathrm{~h}$. Lutein was then isolated and characterized by the procedure described previously (Barua et al. 1973).

Anhydrolutein was prepared from lutein by the method of Budowski, Ascarelli, Gross \& Nir ( 1963 ) with the following modifications. $p$-Toluene sulphonic acid ( $5 \circ \mathrm{mg}$ ) was dissolved in $100 \mathrm{ml}$ benzene by refluxing for $3 \circ \mathrm{min}$ at $70^{\circ}$. The hot solution of $p$-toluene sulphonic acid was added gradually to $100 \mathrm{ml}$ lutein in benzene $(\mathrm{rg} / \mathrm{l})$. The solution was warmed to $80^{\circ}$ and examined spectrophotometrically at intervals of $5 \mathrm{~min}$. When the product showed a single peak at $460-465 \mathrm{~nm}$, the reaction mixture was immediately cooled and neutralized with a dilute solution of $\mathrm{NaHCO}_{3}$. The product was extracted into diethyl ether, washed with water, dried over anyhdrous $\mathrm{Na}_{2} \mathrm{SO}_{4}$ and the solvent was removed by evaporation under reduced pressure. The residue was dissolved in light petroleum ( $10 \mathrm{ml}$ ) and applied to a deactivated alumina $(5 \circ \mathrm{ml}$ water $/ \mathrm{kg}$ ) column. Anhydrolutein appeared as a red zone below the small darkyellow zone of unconverted lutein and was eluted with light petroleum-diethyl ether $(100: 5, \mathrm{v} / \mathrm{v})$ and collected in fractions of about $\mathrm{o} 0 \mathrm{ml}$. The solutions which produced a single peak at $460 \mathrm{~nm}$ were pooled. For further purification, anhydrolutein was chromatographed on a column of MgO-Celite (ro: 10, w/w). Anhydrolutein, which appeared as a red zone, was eluted with light petroleum-acetone (100:5, v/v).

The $R_{F}$ for purified anhydrolutein chromatographed on silica gel, using cyclohexane-diethyl ether as the solvent system, was $0 \cdot 46$, without further resolution; an $R_{F}$ of 0.74 was obtained with the light petroleum-benzene-ethanol solvent system. Anhydrolutein was crystallized from light petroleum at $-5^{\circ}$. The extinction maximum for the crystalline sample was $460 \mathrm{~nm}$ in light petroleum, $475 \mathrm{~nm}$ in chloroform and $465 \mathrm{~nm}$ in benzene.

\section{Spectroscopic examination and estimation of vitamin $A$ and carotenoids}

The visible and ultraviolet spectra of the solutions were obtained using a spectrophotometer (Model DK-2; Beckman Instrument Co. Inc., Fullerton, California, USA). Retinol and dehydroretinol contents were estimated by the procedure described by Barua et al. (1973). Anhydrolutein was estimated using the value 203 $\mathrm{I}$ for the extinction coefficient $\left(E_{10}^{1 \%} \mathrm{~mm}\right)$ at $460 \mathrm{~nm}$ in light petroleum (Savithry et al. 1972). Lutein and other carotenoids were estimated by using values 2200 and 2500 for the $E_{10 \mathrm{~mm}}^{1 \%}$ at $445 \mathrm{~nm}$ and at the wavelength of maximum extinction respectively. 


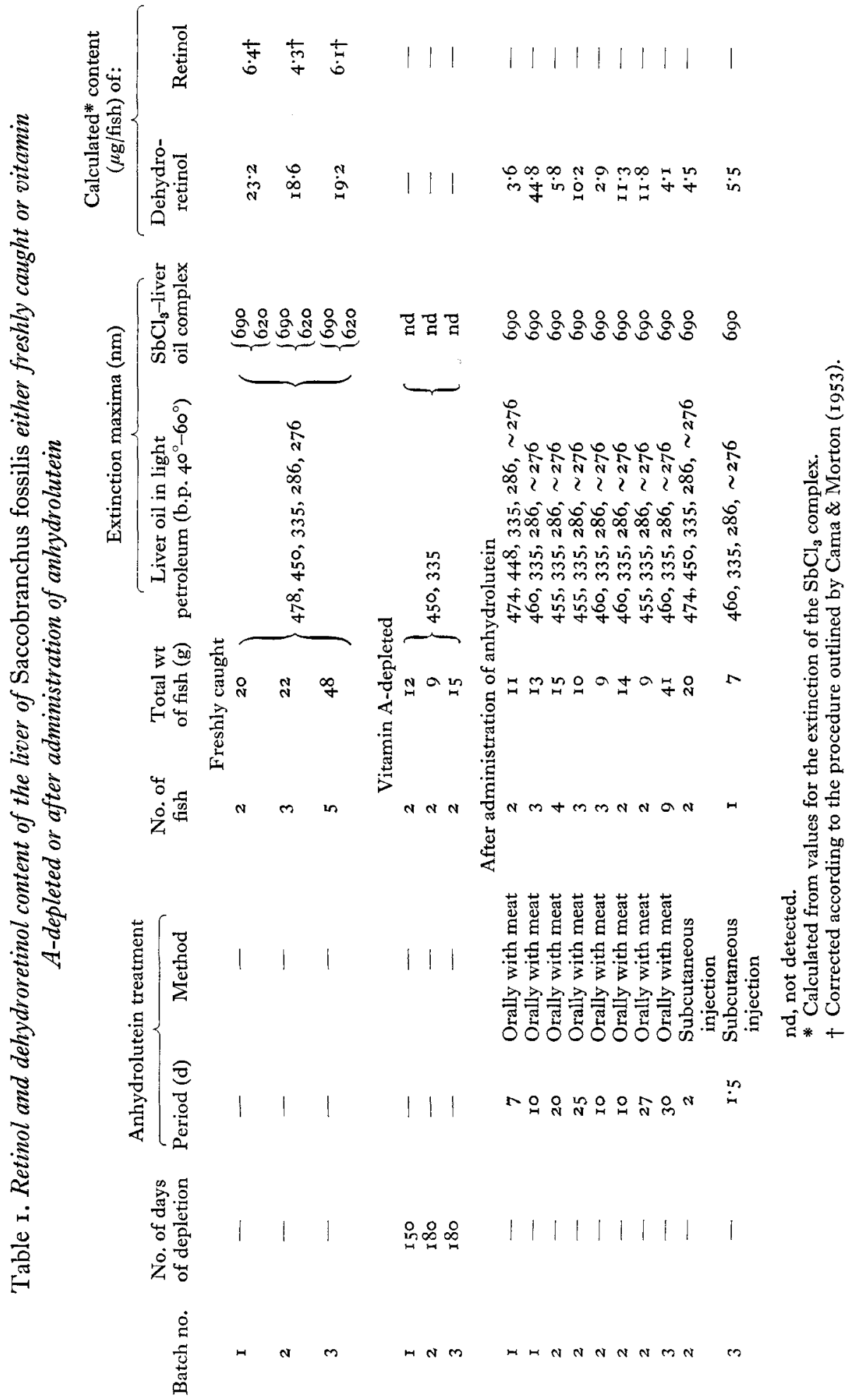




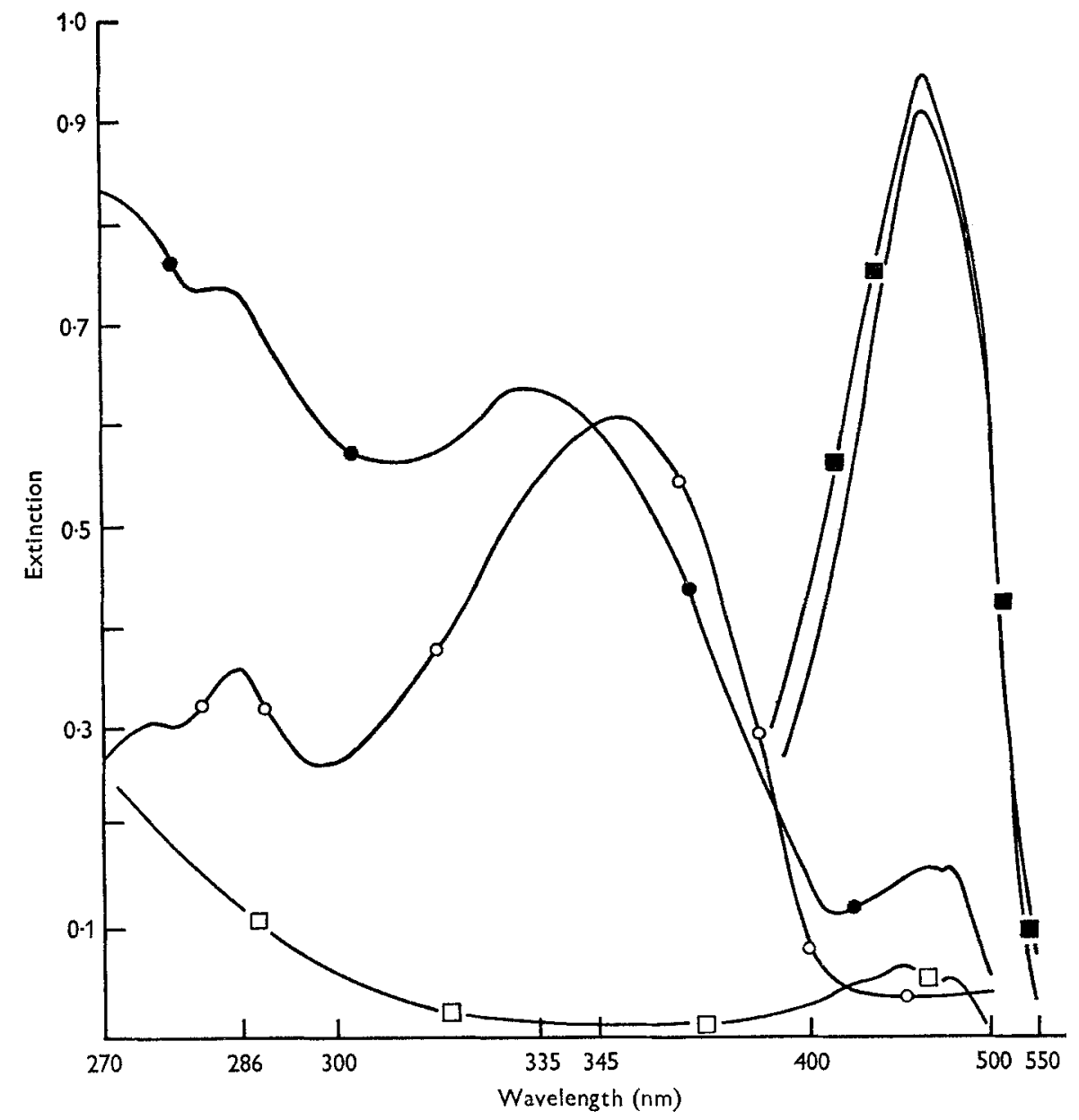

Fig. 1. Visible and ultraviolet spectra, in light petroleum (b.p. $40^{\circ}-60^{\circ}$ ), of liver oils from Saccobranchus fossilis. Vitamin A-depleted fish ( $\square]-\square)$; vitamin A-depleted fish, after oral administration of anhydrolutein (-O); dehydroretinyl ester, isolated by separation on a deactivated alumina column, from liver oils from anhydrolutein-treated fish (Oanhydrolutein, isolated by column chromatography, from liver oil of freshly caught fish (-); anhydrolutein prepared from lutein

\section{Administration of anhydrolutein and lutein}

Crystalline lutein or anhydrolutein was dissolved in a few drops of groundnut oil, mixed with goat meat and given orally to the fish. For subcutaneous injection, the carotenoid was mixed with Tween-8o (Calcutta Chemical Co. Ltd, Calcutta, India), treated with a few $\mathrm{ml}$ water and stirred to get a homogenous dispersion and this was injected into the fish using an Agla micrometer syringe (Wellcome Foundation Ltd, London).

\section{Extraction of liver oil}

Extraction of the oil from the liver or the alimentary canal was done using light petroleum as described by Barua et al. (1973). 


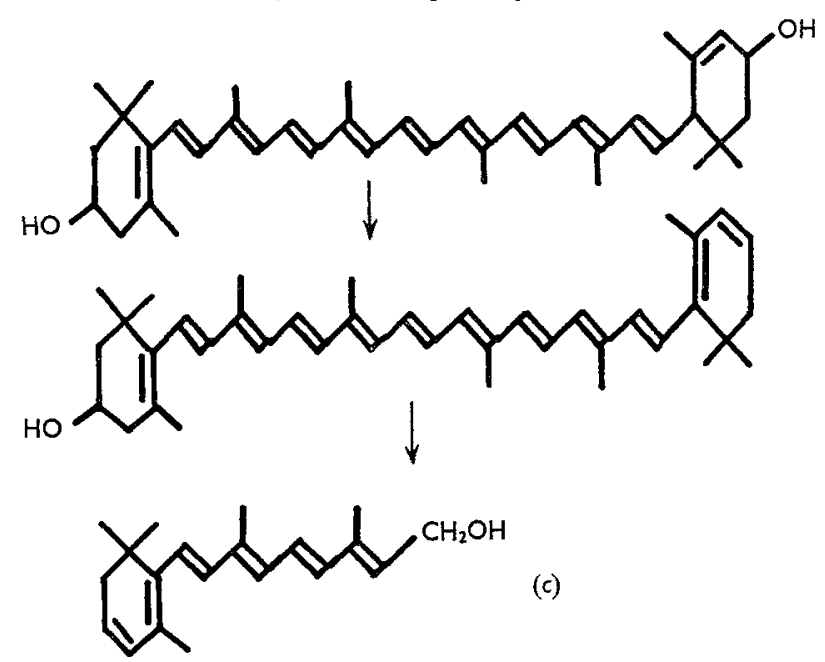

(a)

Fig. 2. Reaction scheme I showing the structures of $(a)$ lutein, $(b)$ anhydrolutein and $(c)$ dehydroretinol.

\section{Fish}

$S$. (Heteropneustes) fossilis was used and the fish were depleted of vitamin A by giving a diet of rice and goat meat, using the procedure outlined by Barua et al. (1973).

\section{RESULTS AND DISCUSSION}

The liver oil of freshly caught $S$. fossilis was found to contain mainly dehydroretinol, with a small amount of retinol. When these fish were maintained on a diet of rice and goat meat, their vitamin A content gradually decreased and was negligible by the end of $5-6$ months (Table I); the extinction at $320-35^{\circ} \mathrm{nm}$ of liver oils from these fish was low (Fig. I) and no colour was produced with antimony chloride reagent (Table I).

Oral administration of anhydrolutein to the vitamin A-depleted fish for a few days resulted in the accumulation of dehydroretinol which was identified by its ultraviolet spectrum (extinction maxima at 335,286 and approximately $276 \mathrm{~nm}$; Table I, Fig. I), which was similar to that of the liver oil of freshly caught $S$. fossilis. In addition, the formation of dehydroretinol was confirmed by the production of a blue complex with $\mathrm{SbCl}_{3}$, which had a maximum extinction at $690 \mathrm{~nm}$ ('Table I). There was also conversion of anhydrolutein into dehydroretinol when the former was administered subcutaneously to the vitamin A-depleted fish (Table r). Column chromatography on deactivated alumina of the liver oil from fish given anhydrolutein resulted in the separation of dehydroretinyl ester (extinction maxima $345^{-350}$ (broad), 286 and $276 \mathrm{~nm}$ (Fig. I); $693 \mathrm{~nm}$ for the $\mathrm{SbCl}_{3}$ complex), and unconverted anhydrolutein (extinction maximum $460 \mathrm{~nm}$ ), together with three other unidentified compounds. It has been reported recently from this laboratory that lutein is the natural carotenoid that can serve as a precursor of dehydroretinol (Barua et al. 1973). It was also reported that the allylic hydroxyl group of lutein can be eliminated as water, with the consequent introduction of a double bond, followed by rearrangement of the double bonds 
Table 2. Results of the separation on deactivated alumina columns of constituents of liver oil from freshly caught Saccobranchus fossilis

(Results for a group of thirty-eight fish, total body-weight $1350 \mathrm{~g}$, total liver weight $12.7 \mathrm{~g}$ )

\begin{tabular}{|c|c|c|c|c|}
\hline $\begin{array}{l}\text { Fraction } \\
\text { no. }\end{array}$ & Eluant & $\begin{array}{l}\text { Extinction maxima } \\
(\mathrm{nm}) \text { in light } \\
\text { petroleum } \\
\left.\text { (b.p. } 40^{\circ}-60^{\circ}\right)\end{array}$ & Compound & $\begin{array}{l}\text { Amount } \\
(\mu \mathrm{g})\end{array}$ \\
\hline $\mathbf{I}$ & Light petroleum (b.p. $40^{\circ}-60^{\circ}$ ) & $474,45^{\circ}, 424$ & $\beta$-carotene & 1822 \\
\hline 2 & Light petroleum & $345,287,276$ & $\begin{array}{l}\text { Dehydroretinyl } \\
\text { ester }\end{array}$ & $145^{8 *}$ \\
\hline $3 \int$ & $\begin{array}{l}\text { Light petroleum } \\
\text {-diethyl ether }\end{array}$ & $472,448,424$ & Unidentified & 86 \\
\hline 4 & $(100: 2, v / v)$ & 460 & $\begin{array}{l}\text { Anhydrolutein } \\
\text { ester }\end{array}$ & 45 \\
\hline 5 & $\begin{array}{l}\text { Light petroleum-diethyl ether } \\
(100: 8, v / v)\end{array}$ & $472,446,420$ & Unidentified & $36 \cdot 6$ \\
\hline 6 & $\begin{array}{l}\text { Light petroleum-diethyl ether } \\
\text { (I00: } 10, \mathrm{v} / \mathrm{v})\end{array}$ & $470,445,420$ & Unidentified & I 98 \\
\hline 7 & $\begin{array}{l}\text { Light petroleum-diethyl ether } \\
(\text { IO०: } 12, \mathrm{v} / \mathrm{v})\end{array}$ & $472,445,422$ & Lutein ester & I 375 \\
\hline 8 & $\begin{array}{l}\text { Light petroleum-diethyl ether } \\
\left.\text { (IO0: } \text { I }_{5}, \mathrm{v} v\right)\end{array}$ & $476,448,424$ & Unidentified & 396 \\
\hline 9 & $\begin{array}{l}\text { Light petroleum-diethyl ether } \\
(\mathrm{r} 00: 20, \mathrm{v} / \mathrm{v})\end{array}$ & $470,442,420$ & Unidentified & $243 \cdot 2$ \\
\hline ro & Diethyl ether (after extrusion) & $472,448,424$ & Unidentified & $40 \cdot 8$ \\
\hline
\end{tabular}

to form anhydrolutein. Once anhydrolutein is formed it may give rise to dehydroretinol. The biosynthesis of dehydroretinol from lutein could, therefore, be represented by reaction scheme I (Fig. 2).

Savithry et al. (1972), during their study of the conversion of anhydrolutein to dehydroretinol, recovered some anhydrolutein from rats after they had been given this compound. During the present study also, some anhydrolutein was recovered after it had been fed to the vitamin A-depleted fish. Therefore, if reaction scheme r correctly describes the biosynthesis of dehydroretinol, it should be possible to isolate, even if in small amounts, some anhydrolutein from freshwater fish containing predominantly dehydroretinol. We therefore studied the natural occurrence of anhydrolutein in these fish. We selected $S$. fossilis which we obtained as freshly caught, fairly big fish from local fish dealers. The liver oil was extracted with light petroleum and the concentrated extract was chromatographed on deactivated alumina columns. The fractions obtained were characterized and the results are shown in Table 2. The liver oil from freshly caught $S$. fossilis contained, in addition to dehydroretinol, anhydrolutein and lutein (as esters). The anhydrolutein ester was converted into the free alcohol which had an extinction maximum at $460 \mathrm{~nm}$ in light petroleum, $465 \mathrm{~nm}$ in cyclohexane and $475 \mathrm{~nm}$ in chloroform. The naturally occurring anhydrolutein (as the alcohol) was further characterized by mixed chromatography using anhydrolutein, prepared from lutein by treatment with $p$-toluene sulphonic acid. Column and thinlayer chromatography did not result in any resolution of the two compounds, establishing their identity. Thin-layer chromatography of naturally occurring anhydro- 
Table 3. Results of the separation on deactivated alumina columns of liver oil from lutein-treated Saccobranchus fossilis

(Results for a group of fifteen fish, total body-weight $60 \mathrm{~g}$, total liver weight $\mathrm{r}^{\circ} \mathrm{I} \mathrm{g}$ )

\begin{tabular}{|c|c|c|c|c|}
\hline $\begin{array}{l}\text { Fraction } \\
\text { no. }\end{array}$ & Eluant & $\begin{array}{l}\text { Extinction maxima } \\
(\mathrm{nm}) \text { in light } \\
\text { petroleum } \\
\left.\text { (b.p. } 40^{\circ}-60^{\circ}\right)\end{array}$ & Compound & $\begin{array}{l}\text { Amount } \\
(\mu \mathrm{g})\end{array}$ \\
\hline I & Light petroleum (b.p. $40^{\circ}-60^{\circ}$ ) & $474,450,424$ & $\begin{array}{r}\text { Residual( ?) } \\
\beta \text {-carotene }\end{array}$ & $7 \cdot 7$ \\
\hline 2 & Light petroleum & $345,286,276$ & $\begin{array}{l}\text { Dehydroretinyl } \\
\text { ester }\end{array}$ & $61 \cdot 06 *$ \\
\hline 3 & $\begin{array}{l}\text { Light petroleum-diethyl ether } \\
(100: 2, v / v)\end{array}$ & 460 & $\begin{array}{l}\text { Anhydrolutein } \\
\text { ester }\end{array}$ & ro.34 \\
\hline 4 & $\begin{array}{l}\text { Light petroleum-diethyl ether } \\
(\mathrm{I} 00: 5, \mathrm{v} / \mathrm{v})\end{array}$ & $33 \circ$ & Unidentified & $\begin{array}{l}\text { Very little } \\
\text { present }\end{array}$ \\
\hline 5 & $\begin{array}{l}\text { Light petroleum-diethyl ether } \\
(100: 12-14, v / v)\end{array}$ & $476,445,422$ & Lutein ester & 20.46 \\
\hline
\end{tabular}

Table 4. Recovery of dehydroretinol, anhydrolutein and unconverted lutein from liver oil from lutein-treated, vitamin $A$-depleted Saccobranchus fossilis after separation on deactivated alumina columns

\begin{tabular}{|c|c|c|c|c|c|c|c|c|}
\hline \multirow[b]{2}{*}{$\begin{array}{c}\text { Expt } \\
\text { no. }\end{array}$} & \multirow[b]{2}{*}{$\begin{array}{l}\text { No. of } \\
\text { fish }\end{array}$} & \multicolumn{2}{|c|}{ Period (d) of } & \multirow{2}{*}{$\begin{array}{c}\text { Time } \\
\text { between } \\
\text { last dose } \\
\text { and death } \\
\text { (h) }\end{array}$} & \multirow{2}{*}{$\begin{array}{c}\text { Approxi- } \\
\text { mate } \\
\text { lutein } \\
\text { dose } \\
(\mu \mathrm{g})\end{array}$} & \multicolumn{3}{|c|}{ Amount recovered $(\mu \mathrm{g})$} \\
\hline & & $\begin{array}{l}\text { Deple- } \\
\text { tion }\end{array}$ & $\underset{\text { treatment }}{\text { Lutein }}$ & & & $\begin{array}{l}\text { Dehydro- } \\
\text { retinol* }\end{array}$ & $\begin{array}{l}\text { Anhydro- } \\
\text { lutein }\end{array}$ & Lutein \\
\hline $\mathbf{I}$ & 14 & 135 & 7 & I6 & 1500 & $37^{\circ} 1$ & $10 \cdot 6$ & $5 \cdot 7$ \\
\hline 2 & I 5 & $15^{\circ}$ & 8 & 16 & 1600 & $6 \mathrm{I} \cdot \mathrm{I}$ & $7 \cdot 9$ & $4 \cdot 2$ \\
\hline 3 & ro & 180 & 10 & 3 & 2000 & $95 \cdot 5$ & $4 \cdot 0$ & $15 \cdot 5$ \\
\hline 4 & I 5 & I 80 & ro & 3 & 2000 & $6 I \cdot x$ & $10 \cdot 34$ & 20.5 \\
\hline
\end{tabular}

lutein (as the alcohol), anhydrolutein prepared from lutein, and liver oil (unsaponified) of freshly caught $S$. fossilis, using silica gel and the solvent system, cyclohexanediethyl ether $(80: 20, \mathrm{v} / \mathrm{v})$, resulted in the detection of anhydrolutein $\left(R_{F} 0.46\right)$ in the fish liver oil. The possibility of the formation of anhydrolutein from lutein as an artifact during the isolation procedure can be ruled out, because lutein from $Z$. mays leaves and anhydrolutein from liver oil of $S$. fossilis were isolated under identical conditions. If anhydrolutein was formed from lutein as an artifact in the liver oil, it would have been possible to detect some anhydrolutein during the isolation of lutein also: we failed to detect any. Lutein was identified in $S$. fossilis liver oil by thin-layer chromatography of the unsaponified liver oil together with authentic lutein using silica gel, when it remained at the origin with cyclohexane-diethyl ether $(80: 20, \mathrm{v} / \mathrm{v})$ and had an $R_{F}$ of 0.53 with light petroleum-benzene-ethanol (60:30:10, by vol.). Further, lutein isolated from fish liver oil was converted into the free alcohol by saponification with alcoholic $\mathrm{KOH}$. The naturally occurring sample of lutein and 
authentic lutein could not be separated by mixed chromatography on columns of deactivated alumina.

There has been no previous convincing report of the occurrence of anhydrolutein in the plant kingdom. Budowski, Ascarelli, Gross, Nir \& Bondi (1964) reported the presence of anhydrolutein in acidulated soya-bean soapstock and showed that anhydrolutein was an artifact formed from lutein during the acidulation of raw soapstock. The present report on the isolation of anhydrolutein from the liver oil of freshly caught $S$. fossilis, therefore, indicates that dietary lutein may be transformed into anhydrolutein by the fish.

To confirm this view experiments were done in which lutein was fed to vitarnin Adepleted fish. The results of a preliminary experiment (Table 4, Expt $\mathrm{I}$ ) indicated that a compound was present which had an extinction maximum at $460 \mathrm{~nm}$, but no emphasis was placed on the correct identity of this compound. Further experiments were, therefore, done to confirm the identity of this compound and these established that lutein-treated, vitamin A-depleted fish contained some anhydrolutein in addition to dehydroretinol and unconverted lutein. The different compounds which were isolated after giving lutein to the vitamin A-depleted fish are shown in Table 3 . Anhydrolutein was identified by the examination of the visible spectra in different organic solvents and by thin-layer chromatography using silica gel. Three mixtures were examined: one contained anhydrolutein (as the alcohol) isolated from the liver oil from lutein-treated fish, after saponification, another contained anhydrolutein prepared chemically from lutein and the third contained a mixture of these two. All the compounds had an $R_{F}$ of 0.46 in cyclohexane-diethyl ether $(80: 20, \mathrm{v} / \mathrm{v})$ and an $R_{F}$ of 0.74 in light petroleum-benzene-ethanol (60:30:10, by vol.), and the mixture was not resolved. The other compounds shown in Table 3 were similarly identified, after saponification where necessary, by their $R_{F}$ values after thin-layer chromatography.

The recoveries for lutein, anhydrolutein and dehydroretinyl ester from luteintreated, vitamin A-depleted S. fossilis are shown in Table 4. As reported in our earlier paper (Barua et al. 1973) the method of oral administration of lutein was such that a considerable quantity of the carotenoid was lost during feeding and therefore only the approximate amount of lutein or anhydrolutein fed to the fish was known.

The isolation of anhydrolutein from liver oils of freshly caught fish as well as from lutein-treated, vitamin A-depleted fish, therefore, supports our view that lutein is the natural carotenoid that can act as a precursor of dehydroretinol, and that the intermediate in this transformation is anhydrolutein (Fig. 2).

The authors thank Professor N. N. Siddhanta, Head of the Department of Chemistry, for providing the necessary facilities. 


\section{REFERENCES}

Barua, A. B., Singh, H. \& Das, R. C. (1973). Br.F. Nutr. 3o, r.

Bolliger, H. R. \& Konig, A. (r969). In Thin-Layer Chromatography and ed., p. 264 [E. Stahl, editor]. London: George Allen \& Unwin.

Budowski, P., Ascarelli, I., Gross, J. \& Nir, I. (1963). Science, N. Y. 142, 969.

Budowski, P., Ascarelli, I., Gross, J., Nir, I. \& Bondi, A. (1964). F. Am. Oil Chem. Soc. 4r, 44I.

Budowski, P. \& Gross, J. (1965). Nature, Lond. 206, I254.

Cama, H. R. \& Morton, R. A. (1953). Analyst, Lond. 78, 74.

Grangaud, R. \& Moatti, J.-P. (1958a). C. r. Séanc. Soc. Biol. 152, 1235.

Grangaud, R. \& Moatti, J.-P. (1958b). C. r. Séanc. Soc. Biol. 152, 1245.

Morton, R. A. \& Creed, R. H. (1939). Biochem. F. 33, 318.

Savithry, K. N., Krishna Mallia, A. \& Cama, H. R. (r972). Indian F. Biochem. Biophys. 9, 325. 